\title{
Pattern of Cardiac Trauma in Sulaimani Province of Southern Kurdistan: 5 Years' Experience
}

\author{
Aram Baram ${ }^{1,2^{*}}$, Goran Majeed ${ }^{3}$, Hewa Sherzad ${ }^{3}$, Ftoon Flah Korea ${ }^{3}$, \\ Rzgar Ghareeb Muhamed ${ }^{3}$, Fahmi H. Kakamad ${ }^{3}$ \\ ${ }^{1}$ Department of Surgery, School of Medicine, Faculty of Medical Sciences, University of Sulaimani, \\ Sulaymaniyah, Iraq \\ ${ }^{2}$ Department of Thoracic and Cardiovascular Surgery, Sulaimani Teaching Hospital, Sulaymaniyah, Iraq \\ ${ }^{3}$ Faculty of Medical Sciences, University of Sulaimani, Sulaymaniyah, Iraq \\ Email: "aram.baramm@gmaail.com, aram.baram@unvisul.edu.iq
}

Received 30 May 2015; accepted 24 August 2015; published 27 August 2015

Copyright (C) 2015 by authors and Scientific Research Publishing Inc.

This work is licensed under the Creative Commons Attribution International License (CC BY).

http://creativecommons.org/licenses/by/4.0/

c) (i) Open Access

\section{Abstract}

Introduction: Cardiac injuries are one of the important causes of death in young population. With aggressive resuscitative therapy and emergency room thoracotomy, the salvage rate of these patients can reach $35 \%$. In this case series the types of presentation, methods of resuscitation, surgical approaches, operative and postoperative outcomes are discussed. Patients and Methods: From January 2009 to January 2014 there were 3157 patients treated for thoracic injuries at Sulaimani university hospital, 14 patients had cardiac injuries. All admitted cases with central chest trauma were submitted to a thorough clinical examination, ECG and eFAST (extended Focused assessment with sonography for trauma) and/or transthoracic echocardiography. Results: Total of 14 cardiac injuries from 3157 causalities were identified, which is $0.44 \%$ of the total admissions. Male gender was predominant (85.7\% vs. 14.28\%) for females. Mechanism of injury was mostly penetrating (85.71\%) among which stabs were majority $(57.14 \%)$ while bullet and shrapnel each constituted (14.28\%). Mean time of interval between the accident and our intervention was 2.96 hours. No diagnostic test was $\mathbf{1 0 0 \%}$ specific and sensitive. Discussion: Cardiac injury regarded as a crucial injury because of its high fatality. It is reported that $10.3 \%$ of emergency surgical operations are thoracic type and about $1 \%$ of them are associated with cardiac injury. Although any penetrating injury to the thorax may injure the heart but those within the box are more suspicious. We conclude that cardiac trauma is a fatal injury but still if the facilities are available the mortality can be minimized.

${ }^{*}$ Corresponding author.

How to cite this paper: Baram, A., Majeed, G., Sherzad, H., Korea, F.F., Muhamed, R.G. and Kakamad, F.H. (2015) Pattern of Cardiac Trauma in Sulaimani Province of Southern Kurdistan: 5 Years' Experience. World Journal of Cardiovascular Surgery, 5, 82-90. http://dx.doi.org/10.4236/wjcs.2015.58014 


\section{Keywords}

\section{Cardiac Trauma, eFAST, Emergency Thoracotomy}

\section{Introduction}

Cardiac injuries are one of the important causes of death in young population. They were firstly reported by ancient Egypt 5000 years ago [1] whereas the first surgical repair was not achieved until 1897 by Rehn who closed a right ventricular stab wound. Subsequently Beck described the physiology and clinical signs of cardiac tamponade [2] [3]. Cardiac injuries resulting in tamponade, rather than exsanguination, have improved survival. Throughout history operative repair of cardiac injuries was considered to be impossible and the first successful cardiorraphy was performed just over a century ago [3].

Majority of these cases die due to the delay in the emergency resuscitations, inadequate transfer methods and delayed operation. Emergency interventions, rapid patient transportation, quick assessment, and immediate operation are lifesaving measures in cardiac trauma cases [3]. With aggressive resuscitativetherapy and emergency room thoracotomy, the salvage rate of these patients can reach up to 35\% [4].

Early diagnosis and surgical management will improve the outcomes of cardiac trauma in general [2]. The diagnosis of life-threatening cardiac injury is very difficult in the emergent situations. However performing parasternal views of the pericardium using sonography may improve the diagnosis of cardiac injuries and it has a very high rate of sensitivity and specificity [5]. Bed side sonography and echocardiography are considered as an excellent method of emergency diagnosis for tamponing and pre-tamponing hemopericardium [3] [5].

During the recent periods of unrest in Kurdistan, our hospital has seen a marked increase in the number of patients with cardiac trauma. As a result, our management of these patients has evolved to the point where we currently have relatively low perioperative morbidityand mortality.

Here we share our management strategy, which is based on a recent 5-year experience with more than 2000 general thoracic surgical emergencies. This report will discuss our current trends with regard to the types of presentation, methods of resuscitation, surgical approaches, operative and postoperative outcomes.

\section{Patients and Methods}

Between January 2009 and January 2014 there were 3157 patients treated for thoracic injuries at the Sulaimani university hospital, Sulaymaniyah, Kurdistan-Iraq. From this huge number of thoracic causalities only 14 patients had cardiac trauma both penetrating and blunt injuries. All the admitted cases with central chest trauma or trauma to the cardiac box was submitted to a thorough clinical examination, immediate ECG and eFAST (Focused assessment with sonography for trauma) and/or transthoracic echocardiography whenever it's available. According to the results of the immediate workup the decision was taken for surgery or observation. In our study apart from clinical examination, eFAST was the most sensitive, rapid, not-expensive highly accurate toll for diagnosing or excluding hemopericardium.

During the entire duration of the study the patients were followed-up for early and late signs of cardiac trauma squeals as infarction, arrhythmias, valvular disorders, failure.

Only one patient lost from follow-up as he was a prisoner and methods of contact with him were difficult.

\section{Results}

Analysis of cardiac trauma registry in eight years in Sulaimani ER Hospital revealed 14 cardiac injuries from total of 3157 causality admissions this equals to $0.44 \%$ of the total admissions. The male gender was predominant $85.7 \%$ and the female was $14.28 \%$. The age range is 5 - 60 years the mean age is 34.28 (Table 1 ). The mean time of interval between the accident and our intervention was 2.96 hours (Table 2). The mechanism of injury was mostly penetrating $85.71 \%$ among which stab was the most causative agent $57.14 \%$ while bullet and shrapnel each constituted $14.28 \%$ (Figure 1). The most common affected site was the $4^{\text {th }}$ ICS $28.57 \%$, the least affected sites were the sternum and epigastrium 7.14\% each (Figure 2). 


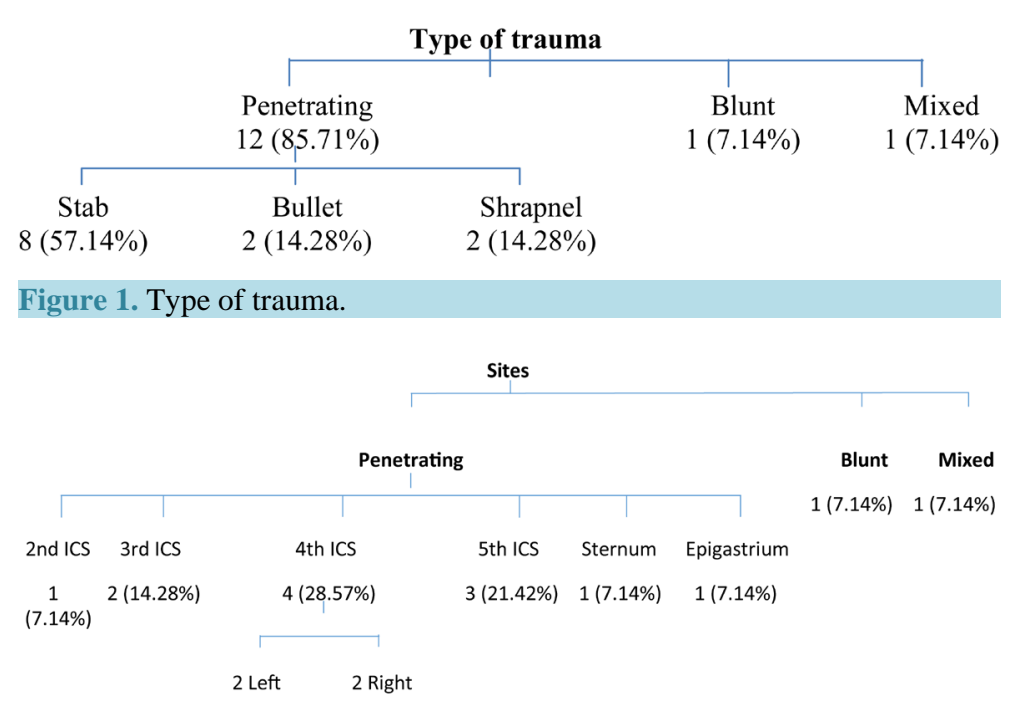

Figure 2. Sites of injury.

Table 1. Patient’s characteristics.

\begin{tabular}{|c|c|c|}
\hline Age & \multicolumn{2}{|c|}{ Gender } \\
\hline \multirow{3}{*}{5 - 60, mean 34.28} & Male & Female \\
\hline & $12(85.71 \%)$ & 2 (14.28\%) \\
\hline & \multicolumn{2}{|c|}{$6: 1$} \\
\hline
\end{tabular}

Table 2. Time to diagnosis.
\begin{tabular}{cc}
\hline \multicolumn{2}{c|}{ Time to Diagnosis } \\
\hline $1-6$ hrs mean $(2.96 \mathrm{hr})$ & $48 \mathrm{hr}$ \\
13 & 1 \\
\hline
\end{tabular}

\subsection{Clinical Presentation}

The most common presentation was shortness of breath $64.28 \%$ followed by chest pain $57.14 \%$, the less encountered presentation was massive hemothorax in one case (7.14\%) and another case presented with a late collapse (7.14\% ) In addition to the other presentations (Table 3).

\subsection{Investigations}

EKG analysis revealed tachycardia in most of the cases 78.57\% (Table 4) in addition to other findings including low voltage, wide QRS $14.28 \%$ each, and LBBB in $7.14 \%$.

FAST assessment of the patients showed pericardial effusion in $57.13 \%$ among which moderate effusion was the most common finding $28.57 \%$. There were two cases with pelvic free fluid (14.28\%), and only one case had a normal FAST though the CXR showed left hemopneumothorax and had moderate percardial effusion intraoperatively (Table 4).

CXR showed hemothorax in $64.28 \%$ of patients, hemopneumothorax in $35.71 \%$, pneumothorax in $25.71 \%$ while enlarged cardiac show was apparent in only $7.14 \%$ of the cases (Figure 3).

Troponin test has not been done in $64.28 \%$ of the cases because of lack of facilities, in the remaining $35.71 \%$, $28.57 \%$ were positive and $7.14 \%$ was negative.

\subsection{Approaches and Intraoperative Course}

LALT was the most used approach 71.42\% (Figure 4) with median sternotomy and Laparotomy + LALT extension 


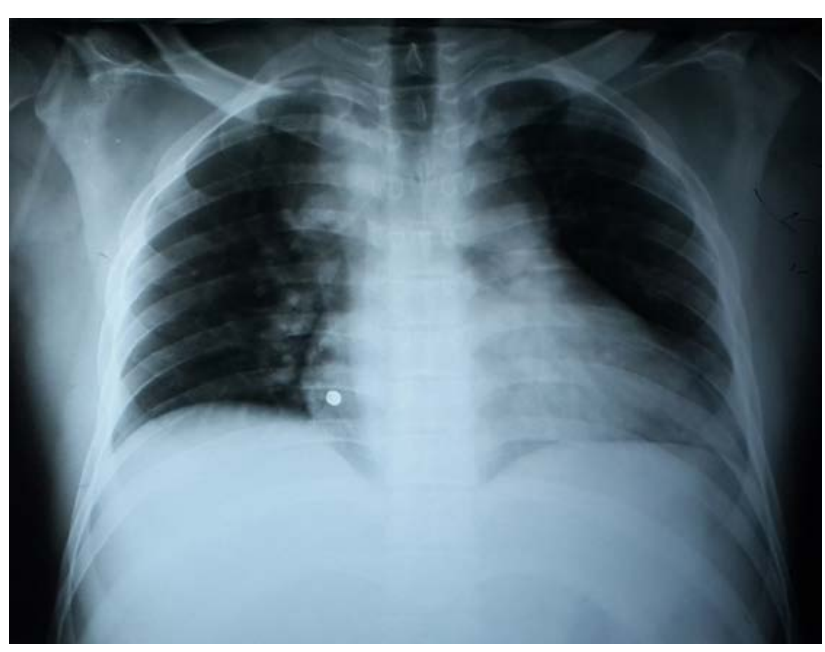

Figure 3. Shrapnel in the right atrium.

Table 3. Signs and symptom.

\begin{tabular}{cccccccccc}
\hline \multicolumn{7}{c}{ Signs and Symptoms } \\
\hline SOB & Chest pain Tachycardia & Hypoxia & Tachypnea Hypotension & Shock & Massive Hemothorax Abdominal pain Late collapse \\
$9(64.28 \%)$ & $8(57.14 \%)$ & $7(50 \%)$ & $5(35.71 \%)$ & $4(28.57 \%)$ & $6(42.85 \%)$ & $3(21.42 \%)$ & $1(7.14 \%)$ & $2(14.24 \%)$ & $1(7.14 \%)$ \\
\hline
\end{tabular}

Table 4. Investigations.

\begin{tabular}{|c|c|c|}
\hline Investigations & Findings & No. (\%) \\
\hline \multirow{4}{*}{ EKG } & Tachycardia & $11(78.57 \%)$ \\
\hline & Low Voltage & $2(14.28 \%)$ \\
\hline & Wide QRS & $2(14.28 \%)$ \\
\hline & LBBB & $1(7.14 \%)$ \\
\hline \multirow{6}{*}{ FAST } & Pericardial Effusion & \\
\hline & Mild & $3(21.42 \%)$ \\
\hline & Moderate & $4(28.57 \%)$ \\
\hline & Massive & $1(7.14 \%)$ \\
\hline & Pelvic free fluid & $2(14.28 \%)$ \\
\hline & Normal & $1(7.14 \%)$ \\
\hline \multirow{5}{*}{ Chest X-ray } & Hemothorax & $9(64.28 \%)$ \\
\hline & Pneumothorax & $5(25.71 \%)$ \\
\hline & Haemopneumoythorax & $5(35.71 \%)$ \\
\hline & Enlarged cardiac shadow & $1(7.14 \%)$ \\
\hline & Foreign body & $1(7.14 \%)$ \\
\hline \multirow{3}{*}{ Troponin test } & Not done & $9(64.28 \%)$ \\
\hline & Positive & $4(28.57 \%)$ \\
\hline & Negative & $1(7.14 \%)$ \\
\hline
\end{tabular}

in $14.28 \%$ each (Table 5). The majority of the cases had a normal intraoperative course 57.42\%, while four cases had low B.P (28.57\%), two cases needed massive blood transfusions (14.28\%), two cases had low U.O.P (14.28\%), one case suffered from SVT (7.14\%) and only two cases got arrested on induction (14.28\%) both died during the first week P.O (Table 6) 


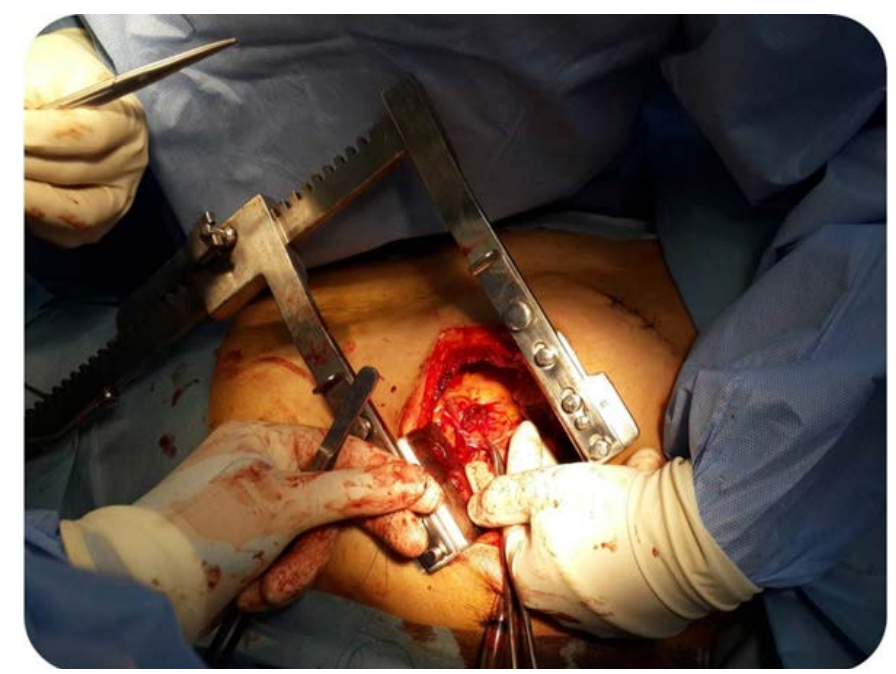

Figure 4. Left ventricular stab wound.

Table 5. Approaches used.

\begin{tabular}{ccc} 
& \multicolumn{2}{c}{ Approach } \\
\hline LALT & Laparotomy + LALT extension & Median Sternotomy \\
$10(71.42 \%)$ & $2(14.28 \%)$ & $2(14.28 \%)$ \\
& Rt 4th ICS wound \\
\hline
\end{tabular}

Table 6. Intraoperative course.

\begin{tabular}{cccccc}
\hline & & \multicolumn{3}{c}{ Intra-operative course } & \\
\hline Normal & Arrest on induction & Low BP & Massive bl. Tansfusion & Low UOP & SVT \\
$8(57.42 \%)$ & $2(14.28 \%)$ & $4(28.57 \%)$ & $2(14.28 \%)$ & $2(14.28 \%)$ & $1(7.14 \%)$
\end{tabular}

Both died after the first week of PO

\subsection{Findings (Table 7, Figure 5)}

Right ventricle was the most commonly injured part (35.71\%) of the cases, and the size of injuries ranged between 3 to $10 \mathrm{~mm}$. Right and left atrial injuries had equal percentages of occurrence of 21.42\% in association with one case of superior pulmonary vein injury with the former and another case of tamponade with the latter. Left ventricle injury occurred in $14.28 \%$, one of the cases had perforation of the fundus of stomach in addition, the patient passed away in $4^{\text {th }}$ POD. The exploration was negative in only one case (7.14\%) for cardiac injury but bowel found in the pericardium.

Eight patients (57.14\%) had successful on table extubation, from those only one patient had persistent T-inversion, LBBB, Anterior wall hypokinesia. Two patients (14.28\%) remained intubated for 24 hrs, of which one patient died in the first post operative day and the other had T inversion in V2-V6 with septal hypokinesia.

Two patients (14.28\%) remained intubated for $48 \mathrm{hrs,} \mathrm{one} \mathrm{of} \mathrm{them} \mathrm{had} \mathrm{impaired} \mathrm{renal} \mathrm{function,} \mathrm{hypotension,}$ compensated H.F, IHD, Ant wall hypokinesia, MFU and LBBB +ST elevation. The last two patients $14.28 \%$ remained intubated for more than 10 days, both of them died due to sepsis and ARDS respectively.

In 7.14\% of cases the FAST showed mild PE while moderate by CT and the CXR showed left hemothorax, intaoperatively the findings were (78\%). In another $7.14 \%$ of cases, again the FAST shows mild PE while moderate by CT, the CXR showed left hemopneumothorax, intraoperatively there was tamponade. The other finding in $7.14 \%$, the FAST was normal, while the CXR showd left hemopneumothorax, intaoperatively there was moderate PE. 


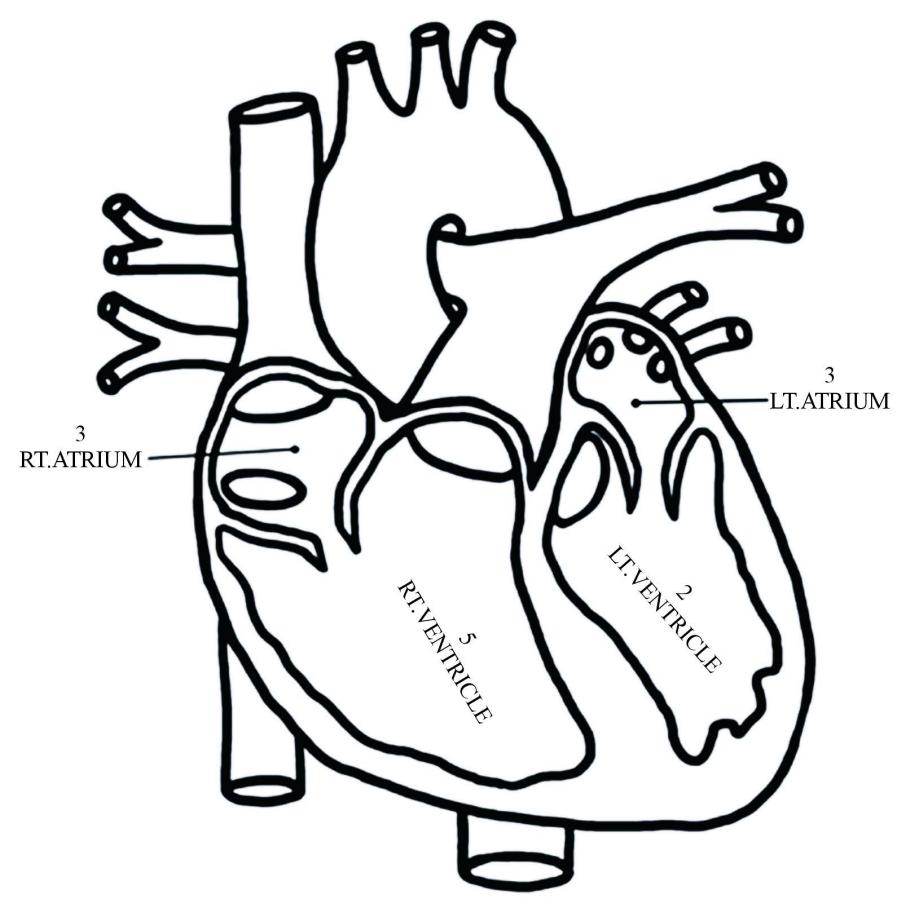

Figure 5. Injured cardiac chambers.

Table 7. Radiological vs. Operative finding of Pericardium.

\begin{tabular}{|c|c|c|c|}
\hline \multicolumn{4}{|c|}{ Radiological Vs. Operative finding of Pericardium } \\
\hline FAST & CXR & CT Scan & Operative finding \\
\hline Mild PE 1 (7.14\%) & Lt Hemothorax & Moderate PE & \\
\hline Mild PE 1 (7.14\%) & Lt hemopneumothorax & Moderate PE & Tamponade \\
\hline Normal 1 (7.14\%) & Lt hemopneumothorax & & Moderate PE \\
\hline
\end{tabular}

\section{Discussion}

Although it is not frequent, cardiac injury is regarded as a crucial injury because of its high fatality [6]. It has been reported that $10.3 \%$ of the emergency surgical operations are of thoracic type and in about $1 \%$ of them are associated with cardiac injury [7]. In our study, among 3157 patients who had thoracic trauma, $0.44 \%$ had associated cardiac injury.

Majority of our patients who had cardiac injury were young aged and predominantly male (Table 1). This is consistent with the current knowledge documented by the other series [8]. These sorts of injuries increase with increasing violence. With regard to the mechanism of injury, it had been found that, in developing countries, stab injuries are more common than gunshot wounds [9]. This is what we found in our series as well; about 85\% of the injuries were due to stab.

The site and the tract of the wound were crucial factors that we depended on mostly to have further investigations to exclude cardiac injuries. Although any penetrating injury to the thorax may injure the heart as well [10], those within the box are more suspicious [3]. In this series, with the exception of one of the patients, in all of the others the sites were within the box area (Figure 2).

Clinical presentations of patients with cardiac trauma vary from the spectrum of hemodynamic stability to the cardiac standstill [3]. Dyspnea was the predominant symptom in our patients, followed by chest pain and abdominal pain (Table 3). Most of our patients presented with one or more of the components of Beck's triad (muffled heart sound, jugular venous distention and hypotension) [11]. But the classical triad was infrequently present (only in 21.4\%). This has also been seen in other series; Jebara V. and Saade B. [12], found that beck's triad which is pathognomonic for tamponade has been seen in $33 \%$ of patients and in $60 \%$ of those with surgi- 
cally proven tamponade.

Early diagnosis of cardiac injury is important to precede surgical intervention as early as possible. Although the site of the injury, the clinical presentations and EKG may alert the surgeon to the possible heart injury, investigations such as chest X-ray, ultrasound (US) and Echocardiography may help to confirm the diagnosis. In some patients who are critically injured, there is no enough time to have further investigations. Such patients should be transferred directly to the operative theater.

Chest X-ray is of great value for evaluating patients with suspected cardiac injuries, especially in those whom the shell doesn't leave the body. In addition, CXR may help the physician in determining further associated injuries [12]. In this study, chest X-ray played a great role in evaluating most of the patients, especially in two of them. In one of the patients the X-ray showed enlarged cardiac shadow (global heart). In the other, there was a metallic foreign body within the shadow of the heart.

Both ultrasonography and echocardiography are non-invasive and inexpensive tools. They are rapid with a high accurate rate in the diagnosis of cardiac injury. Echocardiography has $97 \%$ specificity, $90 \%$ sensitivity and 96\% accuracy in detecting heart injuries [13]. In addition, US reported a high accuracy rate as well. Rozycki and associate [14] found $96.9 \%$ specificity and 100\% sensitivity. On the other hand, there are studies that regard echocardiography and US as ineffective and time consuming tools, especial in the emergency situations [9]. Moreover, these two tools may be difficult to be performed in some situation, for example, in badly positioned patient or in patients with severe chest pain and tenderness. Furthermore, Echocardiography and US may add nothing as a screening tests in situations were hemo or pneumothorax interfering with the quality of the images [13].

Transthoracic sonography was the main diagnostic tool that has been performed in our center to exclude cardiac injury. This is because; echocardiography was not readily available in the emergency room. In our experience, 11 patients underwent eFAST study, only in one of the patients, who had pericardial effusion confirmed during surgery, was missed by sonography. This finding may contribute to false negative result. It appears from this practice, that sonography could be a good alternative measure in diagnosing cardiac injuries. The problem with sonography in assessing cardiac injury is the difficulty in evaluating valve injury. This needs a use of specific probe to exclude valve damage [5].

There are several approaches for the exposure of the heart and mediastinum. Each has its own advantages and disadvantages, and the choice is by the surgeon's preference. Although, some authors prefer median sternotomy, for the good exposure of the heart and mediastinum [12], and the ease in institution of cardiopulmonary bypass [6], if required, others prefer left anterolateral thoracotomy [15]. The latter approach was the preferred one in this series (Table 5). This incision could be performed quickly, provides good exposure to the heart and if needed, further exposure such as sternotomy can be done [15]. Whatever the approach is, it's important to fully prepare and drape the patient prior to the induction of general anesthesia. In this experience, two of the patients developed cardiac arrest. With induction cardiac arrest may happen, especially in hypotensive patient, this is because of the effect of positive pressure ventilation and general anesthesia, which both tend to decrease cardiac preload [3].

The most frequently injured cardiac chamber in this series was the right ventricle, followed by the right and left atrium equally and then left ventricle (Figure 5). This is not exactly consistent with what it has been reported by the other studies. For example, the distribution of involvement of cardiac chambers in Karrel et al. review [16] was; the right ventricle was involved in $42.5 \%$ of the cases, the left ventricle in $33 \%$ of the patients, the right atrium in $15.4 \%$ and the left atrium in $5.8 \%$. All of the repairs were performed with 3.0 prolene, using either horizontal mattress or simple suturing. In none of the repairs, plegets were used. Although there are studies that recommend the routine use of plegets (either Teflon or pericardium) in repairing cardiac injuries [6], others believe that; plegets may increase suture tension and impair the coronary blood flow, and they prefer not to be used unless it is necessary [3].

The overall survival in this series was 11 out of 14 patients with cardiac injury. We had three patients who died. In two of them, the cause of death was not directly related to the cardiac repair. It was due to sepsis and ARDS. While the third patient died due to unknown causes (Figure 6).

\section{Conclusion}

Cardiac trauma is a fatal injury, but still if the facilities are available the mortality can be minimized by immediate well prepared surgical treatment. 


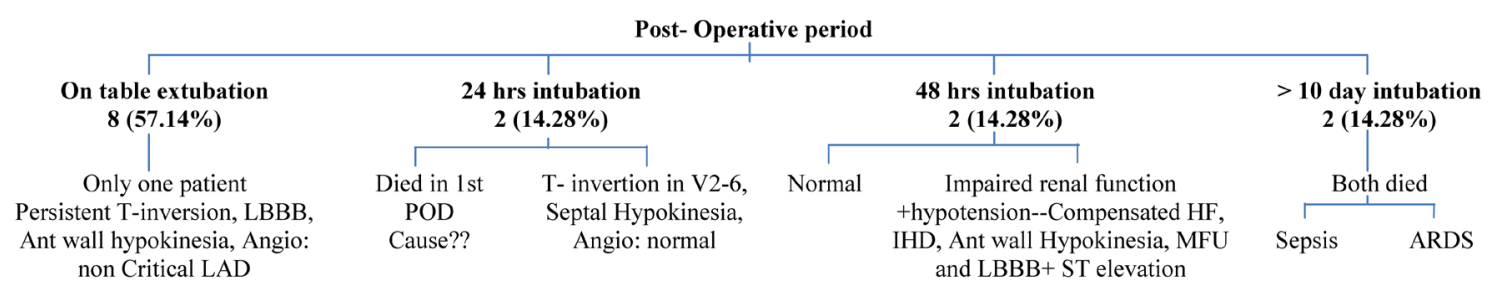

Figure 6. Post-operative period.

\section{Conflict of interest}

None to be declared.

\section{Acknowledgements}

We would like to acknowledge all our personnel who assisted in serving our patients.

\section{References}

[1] Rashid, M.A. and Lund, J.T. (2003) Trauma to the Heart and Thoracic Aorta: The Copenhagen Experience. Interactive Cardiovascular and Thoracic Surgery, 2, 53-57. http://dx.doi.org/10.1016/S1569-9293(02)00099-3

[2] Mataraci, I, Polat, A, Çevirme, D., et al. (2010) Increasing Numbers of Penetrating Cardiac Trauma in a New Center. Turkish Journal of Trauma \& Emergency Surgery, 16, 54-58.

[3] O’Connor, J., Ditillo, M. and Scalea, T. (2009) Penetrating Cardiac Injury. Journal of the Royal Army Medical Corps, 155, 185-190. http://dx.doi.org/10.1136/jramc-155-03-02

[4] Attar, S., Suter, C.M., Hankins, J.R., et al. (1991) Penetrating Cardiac Injuries. The Annals of Thoracic Surgery, 51, 711-716. http://dx.doi.org/10.1016/0003-4975(91)90110-C

[5] Patel, A., Brennig, C., Cotner, J., et al. (2003) Successful Diagnosis of Penetrating Cardiac Injury Using SurgeonPerformed Sonography. The Annals of Thoracic Surgery, 76, 2043-2047. http://dx.doi.org/10.1016/S0003-4975(03)01057-9

[6] Mataraci, İ., Polat, A., Çevirme, D., et al. (2010) Increasing Numbers of Penetrating Cardiac Trauma in a New Center. Turkish Journal of Trauma \& Emergency Surgery, 16, 54-58.

[7] Cingöz, F., Günay, C., Bingöl, H. and Tatar, H. (2007) Kalp yaralanmaları ve acil cerrahi tedavi. Turkish Journal of Cardiology, 10, 64-66.

[8] Kaplan, M., Demirtaş, M., Alhan, C., Aka, S.A. and Dağsalı, S. (1999) Eren E ve ark. Kalp yaralanmaları: 63 vakalık deneyim. Türk Göğ̈̈s Kalp Damar Cerrahisi Dergisi, 7, 287-290.

[9] Campbell, N.C., Thomson, S.R., Muckart, D.J., Meumann, C.M., Van Middelkoop, I. and Botha, J.B. (1997) Review of 1198 Cases of Penetrating Cardiac Trauma. British Journal of Surgery, 84, 1737-1740. http://dx.doi.org/10.1002/bjs.1800841225

[10] Claasen, C.W., O’Connor, J.V., Gens, D., Sikorski, R. and Scalea, T.M. (2010) Penetrating Cardiac Injury: Think outside the Box. Journal of Trauma, 68, E71-E73. http://dx.doi.org/10.1097/ta.0b013e31815edeea

[11] Beck, C.S. (1935) Two Cardiac Compression Triads. The Journal of the American Medical Association, 104, 714-716. http://dx.doi.org/10.1001/jama.1935.02760090018005

[12] Jebara, V. and Saade, B. (1989) Penetrating Wounds to the Heart: A Wartime Experience. The Annals of Thoracic Surgery, 47, 250-253. http://dx.doi.org/10.1016/0003-4975(89)90281-6

[13] Knott-Craig, C.J., Dalton, R.P., Rossouw, G.J. and Barnard, P.M. (1992) Penetrating Cardiac Trauma: Management Strategy Based on 129 Surgical Emergencies over 2 Years. The Annals of Thoracic Surgery, 53, 1006-1009. http://dx.doi.org/10.1016/0003-4975(92)90375-E

[14] Rozycki, G.S., Feliciano, D.V., Ochsner, M.G., et al. (1999) The Role of Ultrasound in Patients with Possible Penetrating Cardiac Wounds: A Prospective Multicenter Study. Journal of Trauma, 46, 543-551. http://dx.doi.org/10.1097/00005373-199904000-00002

[15] Tavares, S., Hankins, J.R., Moulton, A.L., et al. (1984) Management of Penetrating Cardiac Injuries: The Role of Emergency Room Thoracotomy. The Annals of Thoracic Surgery, 38, 183-187. http://dx.doi.org/10.1016/S0003-4975(10)62233-3 
[16] Karrel, R., Shaeffer, M.A. and Franaszek, J.B. (1982) Emergency Diagnosis, Resuscitation, and Treatment of Acute Penetrating Cardiac Trauma. Annals of Emergency Medicine, 11, 497-503.

http://dx.doi.org/10.1016/S0196-0644(82)80073-5 